\title{
Analysis of the Personality, Motivation, Ability, and Environment Affecting Creativity in Japanese Business
}

\author{
Hiroya Hirakimoto \\ University of Hyogo, Kobe, Japan
}

\author{
Rie Watada \\ HRD Institute, LLP, Osaka, Japan
}

\begin{abstract}
Recently, there have been only a few quantitative researches on creativity in business especially in Japan, although creativity is important for business performance. This paper aims to clarify the factors which affect creativity in business. Judging from previous researches, it can be classified that the factors probably associate with creativity into four categories: personality, ability, motivation, and environment. This paper can also aim to verify that CF (creativity factor) could be better predictors for business performance than IQ (intelligence quotient) test score (IQ score). Accordingly, the authors hypothesize that: (1) CF can be found in any factors of personality, ability, motivation, or environment; and (2) CF correlates more closely with performance than IQ score. The authors requested 303 respondents to answer Web-based questionnaires consisting of 565 questions within a set period of time. The respondents belong to sales divisions in Japanese venture businesses. Their supervisors evaluated their creativity using a five-point scale. The authors used their supervisors' evaluation as a criterion variable of creativity to build a multi-regression analysis model. The results showed that the factors, "independence and activeness" and "exciting" are 5\% statistically significant accelerators in the "personality" category; In the "ability", "new combination of ideas", and "decision-making speed" significantly accelerate creativity; In the "motivation", "interest of work", "positive feedback (negative)", and "reward for work" significantly accelerate creativity. In the "environment", there are five significant accelerators, such as "excellent colleague", "criticism of ideas", "autonomy", "conservative atmosphere", and an impediment, such as "excessive workload". Although CF does not correlate with IQ score, it partially correlates with both the TTCT (Torrance Test for Creative Thinking) score and the performance of the respondents. Furthermore, IQ score does not correlate with performance. Consequently, CF could be better predictors for business performance than IQ score.
\end{abstract}

Keywords: creativity, performance management, intellectual ability, human resource management

\section{Introduction}

It is important for Japanese companies to enhance creativity in view of competitive strategy, because Japan faces problems, such as poor natural resources and depopulation.

According to previous researches, talented persons who play important roles not only have special knowledge and are cooperative, but also are creative (Murayama, 2006). Nomura (1967) reported that creativity correlates closely with business performance. Moreover, Getzels and Jackson (1962) and Guilford (1977) suggested that creativity needs a certain level of IQ (intelligence quotient).

Hiroya Hirakimoto, Ph.D., professor, School of Business Administration, University of Hyogo.

Rie Watada, Ph.D., CEO, HRD Institute, LLP. 
Therefore, the authors expect that core human resources along with both high creativity and high IQ will result in good performance, and that Japanese companies will require persons who can create an innovative business model to solve business issues.

Japanese style of management tends to avoid competition and changes in the office. In such a conservative environment, enhancing creativity becomes the most important issue for human resource management. That is to say, only companies which succeed in retaining and developing creative persons can survive in severe competition.

Although creativity is an important issue for business, the authors can find only a few researches on creativity in business.

That is the reason why this research aims to clarify the factors which affect creativity in a business environment.

\section{Definition of Creativity}

The authors can find many researches on creativity. Creativity is being recognized as an important promoter for business success in all organizations (George \& Zhou, 2001; 2002; 2007). Creativity is typically defined as generation or production of ideas that are both novel and useful. Following this definition, the authors use the term "creativity" to refer to a kind of intellectual ability to generate or produce something novel and useful.

The authors reviewed some previous researches in order to rearrange them theoretically according to the viewpoint of factors relating to creativity. As shown in Figure 1, it seems that the previous researches can be categorized into four main approaches: personality, ability, motivation, and environment, the authors surveyed the previous researches along with the four categories in this paper.

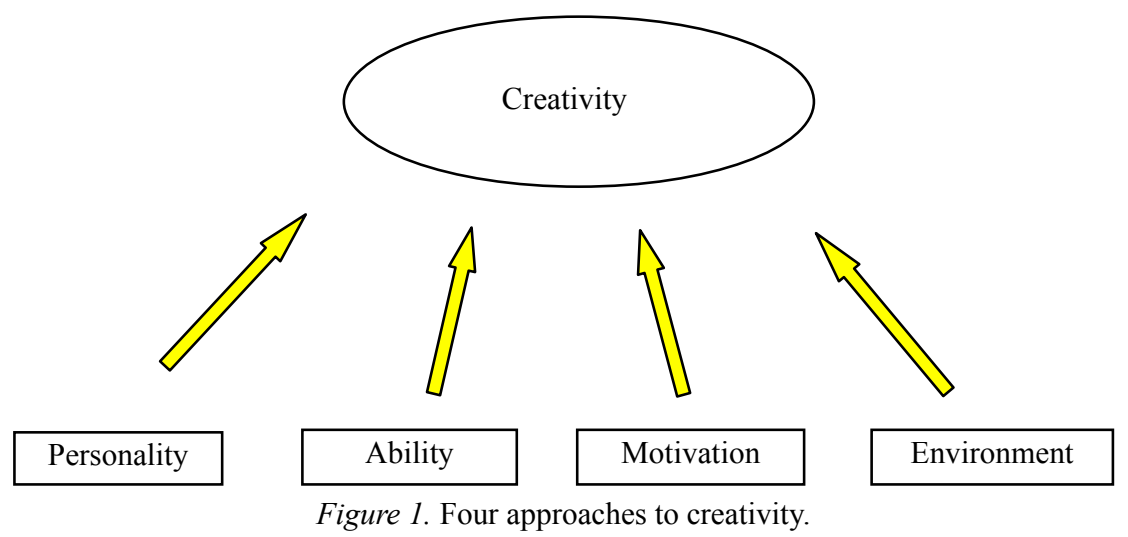

\section{Personality}

The personality approach pays attention to personality traits as factors to predict creativity. In other words, it hypothesizes that there might be common personality traits in creative persons.

Gough (1979) stated that creativity can be judged by a check list consisting of 30 adjectives. The check list is called the CPS (Creative Personality Scale). He also pointed out that creativity evaluated by an expert statistically correlates with CPS score. Oldam and Cummings (1996) demonstrated that CPS, complicated work, non-control supervision, and supportive supervision influenced creativity in a quantitative survey of 171 employees of the manufacturing industry. 
Furthermore, Glynn and Webster (1992) developed a "Adult Playfulness Scale" in a workplace using the data of more than 300 people and confirmed a statistically positive correlation with CPS.

Kirton (1976) classified personality traits toward problem-solving into two types: "innovator" and "adapter". He developed the KAI (Kirton Adaption-Innovation Inventory) which estimates the type of personality trait. KAI consists of originality, effectiveness, and rule/group conformity. Moreover, he insisted that persons who have high originality, low effectiveness, and low conformity tend to be more creative.

Basadur and Finkbeiner (1985) pointed out four dimensions which are "like producing ideas", "do not evaluate ideas at an early stage critically", "valuing new ideas", and "belief that creative thinking is (not) bizarre" as a scale to measure an aptitude contributing to creativity. It was demonstrated that among the four dimensions, "like producing ideas" (Basadur \& Finkbeiner, 1985) and "do not evaluate ideas at an early stage critically" (Runco \& Basadur, 1993) correlate with creativity.

Barron (1956) pointed out that independence of judgment, complicated personality, and enthusiasm for complexity are common personality traits of creative captains in the US Army. MacKinnon (1962) also pointed out that positive self-evaluation, feminine traits (high MF (masculinity-femininity) scores on the Minnesota Multiphasic Personality Inventory), and enthusiasm for complexity and asymmetry are common personality traits of 40 creative architects.

\section{Ability}

The authors reviewed the previous researches from the approach of ability. After Guilford (1977) introduced the approach, Torrance $(1962 ; 1979)$ refined it for practical use. Guilford (1977) suggested using a SI (structure of intelligence) model to recognize intelligence systematically. In the SI model, information is gathered by three factors: contents, products, and operations, and then, the information is classified in a total of 150 domains. Furthermore, he pointed out that intelligence means processing information and assumed that each part of intelligence corresponds to one of the 150 domains.

Torrance (1962) adopted the divergent thinking suggested by Guilford in the SI model and focused his research on the relationship of divergent thinking and creativity. He assumed that divergent thinking promotes creativity. Furthermore, he showed that divergent thinking consists of four dimensions: fluency, flexibility, originality, and elaboration. He proposed using the TTCT (Torrance Test for Creative Thinking) as a scale to measure divergent thinking ability.

Fleming and Weintraub (1962), Lieberman (1977), Alston (1971), Dauw (1965), and Torrance and Dauw (1965) conducted a quantitative analysis using TTCT for children and students. Haven (1965), Torrance and Hansen (1965), and Wallace (1961) conducted surveys on adults. They found a weak positive correlation between originality of TTCT and creative performance. Therefore, it is possible to say that TTCT partially shows criterion-referenced validity.

\section{Motivation}

The authors reviewed the previous researches from the approach of motivation. Amabile, Hill, Hennessey, and Tighe (1994) developed a scale of intrinsic and extrinsic motivation and analyzed the correlation between intrinsic motivation and creativity. Intrinsic motivation includes self-determination, competence, task-involvement, curiosity, and interest. Extrinsic motivation includes evaluation concerns, recognition concerns, competition concerns, monetary concerns, and a focus on the dictates of others. Amabile et al. (1994) developed a questionnaire with 30 items to measure these motivations. As a result of quantitative analysis of 
the relationship between motivation and creativity, they pointed out that intrinsic motivation promotes creativity and that extrinsic motivation does not.

On the contrary, Zhou and Shalley (2003), and Shalley, Zhou, and Oldham (2004) indicated that there are a few researches directly examining a proposition that intrinsic motivation promotes creativity.

Moreover, George (2007) indicated that external motivation might be sources of creativity in organizations. External pressure can motivate employees and it does not necessarily detract creativity. Thus, the previous researches did not support consistently and rigorously a proposition that intrinsic motivation promotes creativity and extrinsic motivation does not, either.

\section{Environment}

Finally, the authors reviewed the approach of environment mainly using some researches by Amabile $(1983 ; 1996 ; 1997)$. The environmental approach assumes that the social environmental factor which surrounds an individual promotes creativity. She developed a scale called KEYS which consists of six factors promoting creativity and two factors impeding creativity. She proposed a quantitative analytical model to measure the environmental factors of creativity. As a result of a quantitative investigation in an American high-tech company of more than 30,000 employees, she discovered a statistically significant difference of six factors between high creative projects and low creative ones. The six factors are: "challenging work", "organizational encouragement", "encouragement by the work group", "supervisory encouragement of creativity", "autonomy or freedom", and "organizational impediments". And the two factors of "enough resources" and "excessive workload" have less difference in the projects than the six factors mentioned above.

In addition to the factors mentioned by Amabile (1983; 1996; 1997), Unworth, Wall, and Carter (2005), and Shalley et al. (2004) pointed out the perception that one is expected and told to generate ideas is a proximal influence on creativity. On the other hand, Ohly, Sonnentag, and Pluntke(2006) concluded that routine work promotes creativity in a field study of high-tech company.

McGraw (1978) showed that expectation of reward obstructs the outcome of heuristic work, although it promotes that of algorithmic work. Furthermore, Amabile (1996) regarded deadline, supervision, and limitation of choice as social limitation factors. These factors which are negative for individual promote algorithmic work and impede heuristic ones like the factor of reward expectation does.

Dijksterhuis and Nordgren (2006) explained the reason why deadline detracts creativity. According to their experimental social-psychology research, they showed that allowing time for unconscious thought leads to better outcomes than relying exclusively on conscious thought. On the contrary, deadline is regarded as a potential creativity promoter (Baer \& Oldham, 2006).

According to the study of Amabile, Goldfarb, and Blackfield (1990), evaluation and monitoring affect creativity negatively. Close monitoring and evaluation pressure detract psychological safety needed in creative endeavor and generation of ideas (George, 2008; Alge, Ballinger, Tangirala, \& Oakley, 2006).

Amabile (1982) also found that children who recognize their work are for acquiring a prize produce a less creative outcome than children who do not. Furthermore, Amabile and Gitomer (1984) pointed out that limitation of choice affects creativity negatively.

The authors can find a lot of previous researches on factors relating to creativity. There is, however, only a few quantitative researches that analyze the correlation between creativity and individual performance in business, with the exception of the study of Nomura (1967). He pointed out that creativity positively correlates 
with the evaluation of performance in his quantitative research on 20 office workers and 27 engineers. Continuously, he also suggested that the correlation between intelligence and evaluation of performance is not significant statistically.

Here, it is noticed that the previous researches on creativity can be categorized into four approaches. Therefore, the authors will try to build an analytical model to capture the four approaches as a whole in this study (see Figure 1) and aim to explore CF (creativity factor).

According to the four approaches from previous researches, we can classify the factors, which probably relate to creativity into four categories: "personality (P category)", "ability (A category)", "motivation (C category)", and "environment". In the analysis, "environment" has two sub-categories: EA (environmental accelerator) and EI (environmental impediment).

After the authors can clarify CF, the authors will also aim to verify that CF can be better predictors for business performance than IQ.

Accordingly, the authors hypothesize as follows:

(1) Hypothesis 1: The factors which affect creativity can be found in any factors of "personality", "ability", "motivation", or "environment".

(2) Hypothesis 2: The factors which affect creativity correlate more closely with performance than IQ.

\section{Method}

The authors requested 303 respondents to separately answer two kinds of Web-based questionnaires consisting of 565 items in total within a set period of time. The authors developed the items in reference to the previous researches mentioned above, and the qualitative research in which the authors interviewed 20 Japanese creative top-managers in 2007.

The respondents belong to sales divisions of a company A in Japanese venture businesses. The reason why the authors selected sales persons is that their performance can be calculated quantitatively and objectively. The questionnaires have two parts. The respondents were required to access their company's Web server and answer each part separately by the announced deadline. Then, the authors sent a reminder to respondents who did not answer yet.

Their supervisors evaluated the creativity of the respondents using a five-point Likert scale (from $5=$ "Strongly agree" to 1 = "Strongly disagree") for ranking each of the items and a higher score indicates a higher creativity of a respondent. As shown in Figure 2, the authors used their supervisors' evaluation as a criterion variable of CV (creativity) to build a multi-regression analysis model.

\begin{tabular}{|l|}
\hline Questionnaire 1: \\
P category (236 items) \\
A category (94 items) \\
C category (56 items) \\
\hline Questionnaire 2: \\
EA category (120 items) \\
EI category (59 items) \\
\hline
\end{tabular}

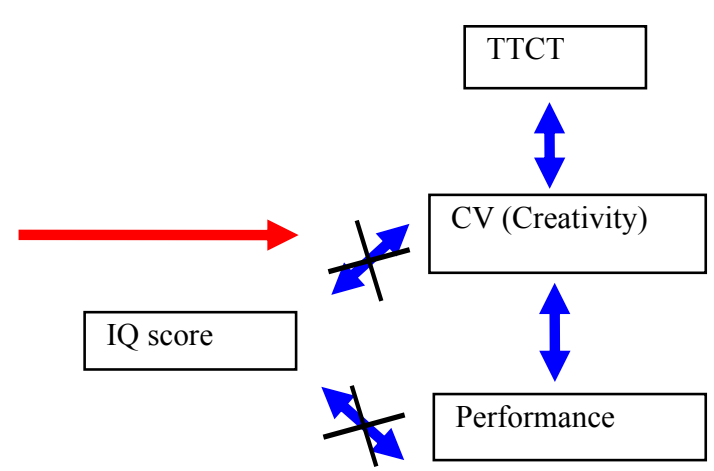

Figure 2. Analysis model. 
According to Murakami (2006), criterion-reference validity contains two validities: predictive validity and convergent validity. The supervisor's evaluation mentioned above corresponds to the former. For the latter, the authors used their TTCT score. The responses to the test items were scored in terms of four criterion components of creativity: fluency, flexibility, elaboration, and originality. The authors used only fluency score which means the production of large numbers of ideas, however, because recent research on TTCT pointed out that TTCT can estimate only fluency in producing ideas (Hassan, 1985; Hocevar, 1979). Thus, the authors adapted fluency of TTCT, because it remains one of the most popular measurements of creativity regardless of its weak reliability.

The authors also used the sales performances of respondents for the past half year (performance), because the authors defined creativity as an utility for business in this research. In other words, even if CF correlated with CV or TTCT score, this research could not be meaningful without CF which can predict performance.

Furthermore, the authors used the IQ test score for discriminant validity, because CF should correlate only with the variables of creativity. IQ score was available, because the company A had developed the IQ test based on Stanford Binet Intelligence Scale and had implemented the test in office. The IQ test calls for 100 verbal and 100 non-verbal questions which can be scored on a 10-point scale with $S D$ (standard deviation).

As Getzels and Jackson (1962) suggested, IQ and creativity each indicate different ability and IQ cannot predict creativity. That is, the authors should confirm that CF do not correlate with IQ score and should ensure discriminant validity in this research.

\section{Results}

\section{Results of Correlation Analysis}

First of all, the authors analyzed the correlation between the 565 items and CV to find out which items closely correlated with CV.

In the P category, consisting of 236 items, 99 items (about 40\%) were 5\% statistically significant, and in the A category, consisting of 94 items, 31 items (about 30\%) were 5\% statistically significant.

In the $\mathrm{C}$ category consisting of 56 items, 11 items (about 20\%) were $5 \%$ statistically significant. The $\mathrm{C}$ category had less significant items than those of the $\mathrm{P}$ and A categories because the $\mathrm{C}$ category had more items with ceiling or floor effects. The authors supposed that these items had less variance.

In the EA category, consisting of 120 items, 26 items (about 20\%) were 5\% statistically significant. In the EI category, consisting of 59 items, 17 items (about 30\%) were 5\% statistically significant.

\section{Results of Exploratory Factor Analysis}

Second, the authors conducted exploratory factor analysis by category. The factors were extracted from the items mentioned in the above section.

The number of the factors was determined by the number of eigenvalue more than 1.00 and a scree test. Then, the authors examined the factor patterns of coefficients of each item. The authors refined the factors structures as a result of excluding the items highly loaded with more than one factor at the same level and less than 0.40 . The authors adopted the mean scores of items highly loaded on each factor as factor scores.

In the P category, the 99 items which closely correlated with CV were analyzed into 10 factors. Sixty five point thirty nine percent of variance was explained by a 10-factor structure. The authors judged that the factor structure had enough explanatory power. In addition, the authors calculated Cronbach's $\alpha$ coefficient to 
examine the reliability of each factor. All the other factors' coefficients were high enough for reliability (more than $\alpha=0.7)$.

In the A category, the 31 items which closely correlated with CV were analyzed into five factors. Sixty one point forty three percent of variance was explained by a five-factor structure. The authors judged that the factor structure had enough explanatory power. In addition, the authors calculated Cronbach's $\alpha$ coefficient to check the reliability of each factor. As a result, all the factors' coefficients were high enough for reliability.

In the $\mathrm{C}$ category, the 11 items which closely correlated with CV were analyzed into three factors. Sixty point sixteen percent of variance was explained by a five-factor structure. The authors judged that the factor structure had enough explanatory power. In addition, the authors calculated Cronbach's $\alpha$ coefficient to examine the reliability of each factor. Although the third factor showed a low coefficient $(\alpha=0.50)$, this factor was consistent for two items and further improvement was impossible. That is the reason why the authors proceeded with the analysis as it is. The other factors' coefficients were enough high for reliability.

In the EA category, the 23 items which closely correlated with CV were analyzed into five factors. Sixty point forty percent of variance was explained by a five-factor structure. The authors judged that the factor structure had enough explanatory power. In addition, the authors calculated Cronbach's $\alpha$ coefficient to examine the reliability of each factor. Except for the fifth factor which showed a slightly low coefficient $(\alpha=$ 0.50 ), the other factors' coefficients were enough high for reliability.

In the EI category, 12 items out of the 17 items which closely correlated with CV were analyzed into three factors. Fifty five point twenty five percent of variance was explained by a three-factor structure. The authors judged that the factor structure had enough explanatory power. In addition, the authors calculated Cronbach's $\alpha$ coefficient to examine the reliability of each factor. As a result, all the factors' coefficients were enough high for reliability.

\section{Results of Multi-regression Analysis}

Third, the authors examined the results of the multi-regression analysis of CV.

The results showed that the two factors: "independence and activeness" and "exciting" were 5\% statistically significant accelerators in the P category. In the A category, "new combination of ideas" and "decision-making speed" significantly accelerated creativity. In the C category, "interest of work", "positive feedback (negative)", and "reward for work" significantly accelerated creativity. In the EA category, there were three significant accelerators, such as "excellent colleague (negative)", "criticism of ideas", and "autonomy". In the EI category, there were two significant impediments, such as "conservative atmosphere (negative)" and "excessive workload" (see Table 1).

\section{Results of Validity Analysis}

Last, but not least, the authors conducted correlation analysis with the 12 above-mentioned CF and performance or TTCT score to confirm convergent validity. Also, the authors carried out correlation analysis with the CF and IQ scores to confirm discriminant validity.

As shown in Table 2, in the P category, "independence and activeness" positively correlated with TTCT score, but "exciting" had no correlation with TTCT score. Both CF positively correlated with performance. Consequently, convergent validity was almost confirmed. Furthermore, neither "independence and activeness" nor "exciting" correlated with IQ score. Consequently, discriminant validity was confirmed. 
Table 1

The Results of Multi-regression Analysis for $\mathrm{CV}$

\begin{tabular}{llcc}
\hline Independent variable & & $\beta$ & $t$-value \\
\hline \multirow{2}{*}{ P category } & Factor 4 (Independence and activeness) & $0.23^{* *}$ & 3.70 \\
& Factor 5 (Exciting) & $0.13^{*}$ & 2.07 \\
\hline & Adjusted $R^{2}=0.09, F=16.46^{* * *}$ & $0.20^{* *}$ & 3.42 \\
A category & Factor 2 (New combination of ideas) & $0.14^{*}$ & 2.45 \\
& Factor 5 (Decision-making speed) & & 4.76 \\
& Adjusted $R^{2}=0.07, F=12.71^{* *}$ & $0.26^{* *}$ & -4.81 \\
C category & Factor 1 (Interest of work) & $-0.27^{* *}$ & 2.73 \\
& Factor 2 (Positive feedback) & $0.15^{* *}$ & -3.99 \\
\hline & Factor 3 (Reward for work) & $-0.14^{* *}$ & -3.93 \\
EA category & Adjusted $R^{2}=0.126, F=15.56^{* *}$ & $-0.24^{* *}$ & 2.28 \\
& Factor 2 (Excellent colleague) & $0.22^{* *}$ & \\
\hline & Factor 4 (Criticism of ideas) & & 4.41 \\
EI category & Factor 5 (Autonomy) & $0.24^{* *}$ & -3.09 \\
& Adjusted $R^{2}=0.12, F=14.54^{* *}$ & $-0.17^{* *}$ & \\
\hline
\end{tabular}

Notes. Dependent variable: $\mathrm{CV} ;{ }^{* * *} p<0.001,{ }^{* *} p<0.01,{ }^{*} p<0.05, \beta$ : standard partial regression coefficient.

In the A category, "new combination of ideas" positively correlated with TTCT score, but "decision-making speed" had no correlation with TTCT score. "decision-making speed" positively correlated with performance, but "new combination of ideas" did not (see Table 2). Consequently, convergent validity was partially confirmed. Furthermore, neither "new combination of ideas" nor "decision-making speed" correlated with IQ score. Consequently, discriminant validity was confirmed.

Table 2

The Results of Correlation Analysis for Validity (P category)

\begin{tabular}{lllll}
\hline & & IQ score & Performance & TTCT score \\
\hline \multirow{2}{*}{ P category } & Factor 4 (Autonomy and exciting) & -0.07 & $0.22^{* *}$ & $0.26^{*}$ \\
& Factor 5 (Exciting) & -0.03 & $0.22^{* *}$ & 0.19 \\
\hline \multirow{2}{*}{ A category } & Factor 2 (New combination of ideas) & -0.04 & 0.09 & $0.43^{* *}$ \\
& Factor 5 (Decision-making speed) & -0.02 & $0.16^{* *}$ & 0.19 \\
\hline \multirow{3}{*}{ C category } & Factor 1 (Interest of work) & 0.05 & $0.142^{*}$ & 0.24 \\
& Factor 2 (Affirmative evaluation of work) & 0.11 & -0.07 & 0.05 \\
& Factor 3 (Reward for work) & 0.01 & $0.149^{*}$ & $0.27^{*}$ \\
EA category & Factor 2 (Excellent colleague) & $0.13^{*}$ & -0.03 & 0.03 \\
& Factor 4 (Criticism of ideas) & 0.06 & 0.00 & -0.17 \\
\hline \multirow{2}{*}{ EI category } & Factor 5 (Autonomy) & 0.11 & 0.08 & 0.20 \\
\hline
\end{tabular}

Notes. ${ }^{* *} p<0.01,{ }^{*} p<0.05$.

In the C category, "reward for work" positively correlated with TTCT score, but "interest of work" and "positive feedback" had no correlation with TTCT score. "Interest of work" and "reward for work" positively 
correlated with performance. Consequently, convergent validity was confirmed except for "positive feedback". Furthermore, all of the three CF had no correlation with IQ score. Consequently, discriminant validity was confirmed.

In the EA category, none of the three factors correlated with TTCT score. Furthermore, "excellent colleague" had a weak correlation with IQ score. Consequently, neither convergent validity nor discriminant validity was confirmed.

In the EI category, only "conservative atmosphere" positively correlated with TTCT score. Consequently, convergent validity was limitedly confirmed. Furthermore, both CFs had no correlation with IQ score. Consequently, discriminant validity was confirmed.

As shown in Table 3, IQ score did not correlate with performance. Thus, IQ score could not predict performance.

Table 3

The Result of Correlation Analysis Between IQ and Performance

\begin{tabular}{ll}
\hline & IQ score \\
\hline Performance & -0.07 \\
\hline
\end{tabular}

\section{Discussion}

The authors will discuss the $12 \mathrm{CFs}$ indicated by the above-mentioned statistic analysis.

The results of the P category analysis indicated as follows: Personality factors, such as active behavior, competitive attitude, and enjoyable are exciting and positively affect creativity in business. That is, a person who actively creates social relationships and is entertaining around people can exhibit higher creativity, and a person who prefers exciting competition to a cooperative relationship can exhibit higher creativity.

The results of the A category analysis indicated as follows: Ability factors, such as combining different ideas in unexpected ways and making decisions promptly positively affect creativity in business. Thus, this suggests that divergent thinking which creates imaginative ideas and prompts judgment on the effectiveness of these ideas is also important for creativity.

The results of the $\mathrm{C}$ category analysis indicated as follows: Motivation factors, such as enjoying a job with passion and desiring monetary reward positively affect creativity in business. On the contrary, a factor such as desiring affirmative assessment and appreciation negatively affects creativity in business. This result was unexpected. That is, not only intrinsic motivation, but also extrinsic motivation positively affects creativity in business.

The results of the EA category analysis indicated as follows: Environment factor, such as existence of excellent colleagues detracts creativity in business. On the contrary, criticizing ideas positively affect creativity in business. These results were unexpected. Moreover, respecting autonomy positively affects creativity in business.

The results of the EI category analysis indicated as follows: The environment factor of a conservative atmosphere positively affects creativity in business. This result was unexpected. The environment factor of excessive workload negatively affects creativity in business, as we have expected.

The results of validity analysis were as follows: In regard to discriminant validity, 11 CFs out of 12 had no correlation with IQ. That is, almost all CFs related more to a different aspect of intelligence than IQ. In regard 
to convergent validity, five CFs positively correlated with "performance" and four CFs positively correlated with TTCT.

Almost all CFs estimated CV and correlated with "performance". On the contrary, IQ correlated with neither CF nor "performance". Consequently, CFs could be better predictors for business performance than IQ (see Table 4).

Table 4

Results of Validity Analysis

\begin{tabular}{|c|c|c|c|}
\hline Category & $\mathrm{CF}$ & Discriminant validity & Convergent validity \\
\hline \multirow{2}{*}{$P$} & Independence and activeness & ○ & ० \\
\hline & Exciting & $\circ$ & $\Delta$ \\
\hline \multirow{2}{*}{ A } & New combination of ideas & O & $\Delta$ \\
\hline & Decision-making speed & ○ & $\Delta$ \\
\hline \multirow{3}{*}{$\mathrm{C}$} & Interest of work & O & $\Delta$ \\
\hline & Positive feedback & $\circ$ & $\times$ \\
\hline & Reward for work & $\circ$ & ○ \\
\hline \multirow{3}{*}{ EA } & Excellent colleague & $\times$ & $\times$ \\
\hline & Criticism of ideas & $\circ$ & $\times$ \\
\hline & Autonomy & 0 & $x$ \\
\hline \multirow{2}{*}{ EI } & Conservative atmosphere & O & $\Delta$ \\
\hline & Excessive workload & o & $\times$ \\
\hline
\end{tabular}

Notes $. \circ=$ perfectly confirmed; $\Delta=$ partially confirmed; $\times=$ not confirmed.

\section{Implications for Practice}

The authors would like to propose implications for practice and future research on the basis of the above-mentioned analysis.

Most Japanese companies conventionally adopt an IQ test as a measurement of an intellectual ability to select talented persons. The analytical results, however, suggest that IQ score does not correlate with any performance. Thus, it is risky to only depend on an IQ test for employment and assessment of human resources. On the other hand, it is clear that the CF examined in this research can predict meaningfully the performance of employees. Thus, selecting and assessing employees based on CF evaluation means that the authors can efficiently employ high performers in business.

Furthermore, the authors can utilize CF measurement to find creative persons, because it is related to TTCT score. Moreover, It is suggested that the CF measurement can provide a strong advantage for companies, if they need creative employees for superior competitive strength.

These considerations invite further empirical investigation.

\section{Limitations and Future Research}

This research has three limitations. Primarily, it is about the sampling of the respondents to the questionnaires. In this research, the authors conducted research on the sales employees in a specific company. Therefore, it makes generalization of the conclusion difficult.

Second, it is about a variable to measure creativity. The authors adopted a subjective rating done by the respondents' supervisors. Although the authors tried to make the rating as objective as possible, it needs to 
search for more objective and qualitative indices of rating creativity in the future.

Third, this research included large numbers of questions. The authors requested the respondents to twice answer a total of 565 items. It demanded considerable time and energy for the respondents to answer the questionnaires. It might be possible that an answer was distorted by respondent fatigue.

On the basis of the above-mentioned limitations, the authors need to improve the questionnaires so that respondents can answer them more easily in a shorter time. Moreover, the authors should conduct more research using business people who are engaged in various occupations in various industries.

Further elucidation of the factors which affect creativity awaits future studies.

\section{References}

Alge, B. J., Ballinger, G. A., Tangirala, S., \& Oakley, J. L. (2006). Information privacy in organizations: Empowering creative and extrarole performance. Journal of Applied Psychology, 9, 221-232.

Alston, D. J. (1971). A comparison of motor creativity with verbal creativity and figural creativity of black culturally deprived from children. Greensboro: University of North Carolina.

Amabile, T. M. (1982). Children's artistic creativity: Detrimental effect of competition in a field setting. Personality and Social Psychology Bulletin, 8, 573-578.

Amabile, T. M. (1983). The social psychology of creativity: A componential conceptualization. Journal of Personality and Social Psychology, 45, 357-376.

Amabile, T. M. (1996). Creativity in context: Update to the social psychology of creativity. West View Press.

Amabile, T. M. (1997). How to kill creativity. In Harvard Business Review on Breakthrough Thinking.

Amabile, T. M., \& Gitomer, J. (1984). Children's artistic creativity: Effects of choice in task materials. Personality and Social Psychology Bulletin, 10, 209-215.

Amabile, T. M., Goldfarb, P., \& Blackfield, S. C. (1990). Social influences on creativity: Evaluation, cognition, and surveillance. Creativity Research Journal, 3, 6-21.

Amabile, T. M., Hill, K. G., Hennessey, B. A., \& Tighe, E. M. (1994). The work preference inventory: Assessing intrinsic and extrinsic motivational orientations. Journal of Personality and Social Psychology, 66(5), 950-967.

Baer, M., \& Oldham, G. R. (2006). The curvelinear relation between experienced creative time pressure and creativity: Moderating effect of openness to experience and support for creativity. Journal of Applied Psychology, 91, 963-970.

Barron, F. (1956). The disposition toward originality. The Journal of Abnormal and Social Psychology, 51, 478-485.

Basadur, M., \& Finkbeiner, C. T. (1985). Measuring preference for ideation in creative problem-solving training. The Journal of Applied Behavioral Science, 21, 37-49.

Dauw, D. C. (1965). Life experiences, vocational needs and choices of original thinkers and good elaborators (Doctoral dissertation, University of Minnesota).

Dijksterhuis, A., \& Nordgren, L. R. (2006). A theory of unconscious thought. Perspectives on Psychological Science, 1, 95-109.

Fleming, E. S., \& Weintraub, S. (1962). Attitudinal rigidity as a measure of creativity in gifted children. Journal of Educational Psychology, 53, 81-85.

George, J. M. (2007). Dialectics of creativity in complex organizations. In T. Davila, M. J. Epstein, \& R. Shelton (Eds.), The creative enterprise: Managing innovative organizations and people (Vol. 2, pp. 1-15). Westport, C. T.: Praeger.

George, J. M. (2008). Creativity in organizations. In The academy of management annals (Vol. 1, pp. 439-477).

George, J. M., \& Zhou, J. (2001). When openness to experience and consciousness are related to creative behavior: An interactional approach. Journal of Applied Psychology, 86, 513-524.

George, J. M., \& Zhou, J. (2002). Understanding when bad moods foster creativity and good ones don't: The role of context and clarity of feelings. Journal of Applied Psychology, 87, 687-697.

George, J. M., \& Zhou, J. (2007). Dual tuning in a supportive context: Joint contributions of positive mood, negative mood, and supervisory behaviors to employee creativity. Academy of Management Journal, 50, 605-622.

Getzels, J. W., \& Jackson, P. W. (1962). Creativity and intelligence: Explorations with gifted students. New York: Wiley.

Glynn, M. A., \& Webster, J. (1992). The adult playfulness scale: An initial assessment. Psychological Reports, 71, 83-103. 
Gough, H. G. (1979). A creative personality scale for the adjective check-list. Journal of Personality and Social Psychology, 37, 1398-1405.

Guilford, J. P. (1977). Way beyond the IQ. Buffalo, N. Y.: Creative Education Foundation.

Hassan, M. A. (1985). Construct validity of Torrance t-tests of creative thinking: A confirmatory factor analytic study. UMI Dissertation Services.

Haven, G. A. (1965). Creative thought, productivity, and the self-concept. Psychological Reports, 16, 750-752.

Hocevar, D. (1979). Ideational fluency as a confounding factor in the measurement of originality. Journal of Educational Psychology, 71(2), 191-196.

Kirton, M. (1976). Adaptors and innovators: A description and measure. Journal of Applied Psychology, 61, 622-629.

Lieberman, J. N. (1977). Playfulness. New York: Academic Press.

MacKinnon, D. W. (1962). The nature and nurture of creative talent. American Psychologist, 17, 484-495.

McGraw, K. (1978). The detrimental effects of reward on performance: A literature review and a prediction model. In M. Lepper, \& D. Greene (Eds.), The hidden costs of reward. Hillsdale, N. J.: Erlbaum.

Murakami, N. (2006). Shinrisyakudo no tsukurikata. Kitaohji Shobo.

Murayama, H. (2006). Jouhousouzougatakigyou: Jouhousouzourensa no housoku to souzougatajinzai no katsuyou. Fukurou Shuppan.

Nomura, K. (1967). Souzousei test no genri to sono sokuteihou. In A. Onda (Ed.), Souzousei no kaihatsu to hyo uka (pp. 308-344). Meiji Tosho.

Ohly, S., Sonnentag, S., \& Pluntke, F. (2006). Routinization, work characteristics and their relationships with creative and proactive behaviors. Journal of Organizational Behavior, 27, 257-279.

Oldam, G. R. \& Cummings, A. (1996). Employee creativity: Personal and contextual factors at work. Academy of Management Journal, 39(3), 607-634.

Runco, M. A., \& Basadur, M. (1993). Assessing ideational and evaluative skills and creative styles and attitudes. Creativity and Innovation Management, 2(3), 166-173.

Shalley, C. E., Zhou, J., \& Oldham, G. R. (2004). Effects of personal and contextual characteristics on creativity: Where should go from here? Journal of Management, 30, 933-958.

Torrance, E. P. (1962). Guiding creative talent. Englewood Cliffs, N. J.: Prentice-Hall.

Torrance, E. P. (1979). The search for satori and creativity. New York: Creative Education Foundation.

Torrance, E. P., \& Dauw, D. C. (1965). Aspirations and dreams of three groups of creativity gifted high school seniors and a comparable unselected group. Gifted Child Quarterly, 9, 177-182.

Torrance, E. P., \& Hansen, E. (1965). The question-asking behavior of highly creative and less creative basic business teachers identified by a paper and pencil test. Psychological Reports, 17, 815-818.

Unworth, K. L., Wall, T. D., \& Carter, A. (2005). Creative requirement: A neglected construct in the study of employee creativity? Group and Organization Management, 30, 541-560.

Wallace, H. R. (1961). Creative thinking: A factor in sales productivity. Vocational Guidance Quarterly, 10, $223-226$.

Zhou, J., \& Shalley, C. E. (2003). Research on employee creativity: A critical review and directions for future research. In J. J. Martocchio, \& G. R. Ferris (Eds.), Research in personnel and human resource management (Vol. 22, pp. 165-217). Oxford: Elsevier Science. 